\title{
Diagnosis and management of dementia with Lewy bodies
}

\author{
Fourth consensus report of the DLB Consortium \\ OPEN
}

Ian G. McKeith, MD,

F Med Sci

Bradley F. Boeve, MD

Dennis W. Dickson, MD

Glenda Halliday, $\mathrm{PhD}$

John-Paul Taylor, PhD,

MRC Psych

Daniel Weintraub, MD

Dag Aarsland, MD

James Galvin, MD, MPH

Johannes Attems, MD

Clive G. Ballard, MRC

Psych, MD

Ashley Bayston, BA, LLB

Thomas G. Beach, MD,

$\mathrm{PhD}$

Frédéric Blanc, MD, PhD

Nicolaas Bohnen, MD,

$\mathrm{PhD}$

Laura Bonanni, MD,

$\mathrm{PhD}$

Jose Bras, $\mathrm{PhD}$

Patrik Brundin, MD,

$\mathrm{PhD}$

David Burn, MD, FRCP

Alice Chen-Plotkin, MD

John E. Duda, MD

Omar El-Agnaf, $\mathrm{PhD}$

Howard Feldman, MD,

FRCP

Tanis J. Ferman, PhD

Dominic ffytche, MD

Hiroshige Fujishiro, MD

Douglas Galasko, MD

Jennifer G. Goldman,

MD, MS

Stephen N. Gomperts,

$\mathrm{MD}, \mathrm{PhD}$

Neill R. Graff-Radford,

$\mathrm{MD}$

Lawrence S. Honig, MD, $\mathrm{PhD}$

Alex Iranzo, MD, PhD

Author list continued on next page

\section{ABSTRACT}

The Dementia with Lewy Bodies (DLB) Consortium has refined its recommendations about the clinical and pathologic diagnosis of DLB, updating the previous report, which has been in widespread use for the last decade. The revised DLB consensus criteria now distinguish clearly between clinical features and diagnostic biomarkers, and give guidance about optimal methods to establish and interpret these. Substantial new information has been incorporated about previously reported aspects of DLB, with increased diagnostic weighting given to REM sleep behavior disorder and ${ }^{123}$ iodine-metaiodobenzylguanidine (MIBG) myocardial scintigraphy. The diagnostic role of other neuroimaging, electrophysiologic, and laboratory investigations is also described. Minor modifications to pathologic methods and criteria are recommended to take account of Alzheimer disease neuropathologic change, to add previously omitted Lewyrelated pathology categories, and to include assessments for substantia nigra neuronal loss. Recommendations about clinical management are largely based upon expert opinion since randomized controlled trials in DLB are few. Substantial progress has been made since the previous report in the detection and recognition of DLB as a common and important clinical disorder. During that period it has been incorporated into DSM-5, as major neurocognitive disorder with Lewy bodies. There remains a pressing need to understand the underlying neurobiology and pathophysiology of DLB, to develop and deliver clinical trials with both symptomatic and disease-modifying agents, and to help patients and carers worldwide to inform themselves about the disease, its prognosis, best available treatments, ongoing research, and how to get adequate support. Neurology ${ }^{\circledR}$ 2017;89:88-100

\section{GLOSSARY}

$\mathbf{A D}=$ Alzheimer disease; $\mathbf{C H E I}=$ cholinesterase inhibitor $\mathbf{D A T}=$ dopamine transporter $\mathbf{D L B}=$ dementia with Lewy bodies; DSM-5 = Diagnostic and Statistical Manual of Mental Disorders, 5th edition; LB = Lewy body; $\mathbf{M C l}=$ mild cognitive impairment; MIBG = metaiodobenzylguanidine; MMSE = Mini-Mental State Examination; MTL = medial temporal lobe; PD = Parkinson disease; PSG = polysomnography; RBD = REM sleep behavior disorder

The Dementia with Lewy Bodies (DLB) Consortium last reported on diagnosis and management in December 2005, and its recommendations have been widely cited for both clinical and research use. ${ }^{1,2}$ Changes made to the diagnostic criteria at that time increased diagnostic sensitivity for DLB, ${ }^{\text {e1 }}$ but detection rates in clinical practice remain suboptimal, ${ }^{3}$ with many cases missed or misdiagnosed, usually as Alzheimer disease (AD). The revised DLB criteria presented here incorporate new developments since then and result from a review process that combined the reports of 4 multidisciplinary, expert working groups with a meeting that included patient and care partner participation (appendix e-1 at Neurology.org). The Consortium recognizes increasing interest in detecting early-stage disease; prodromal DLB criteria are in development and will be reported separately.

SUMMARY OF CHANGES While maintaining their previous structure, the revised DLB clinical diagnostic criteria improve on earlier versions ${ }^{1,2}$ by distinguishing clearly between clinical features and diagnostic

Author affiliations are provided at the end of the article.

Members of the DLB Consortium are listed at Neurology.org.

Go to Neurology.org for full disclosures. Funding information and disclosures deemed relevant by the authors, if any, are provided at the end of the article. The Article Processing Charge was paid by NIHR Newcastle Biomedical Research Centre in Ageing and Long-Term Conditions.

This is an open access article distributed under the terms of the Creative Commons Attribution License 4.0 (CC BY), which permits unrestricted use, distribution, and reproduction in any medium, provided the original work is properly cited. 
Kejal Kantarci, MD, MS

Daniel Kaufer, MD

Walter Kukull, PhD

Virginia M.Y. Lee, PhD

James B. Leverenz, MD

Simon Lewis, MBBCh, MD

Carol Lippa, MD

Angela Lunde, MA

Mario Masellis, MD, PhD

Eliezer Masliah, MD

Pamela McLean, PhD

Brit Mollenhauer, MD

Thomas J. Montine, MD, $\mathrm{PhD}$

Emilio Moreno, MD, $\mathrm{PhD}$

Etsuro Mori, MD, PhD

Melissa Murray, $\mathrm{PhD}$

John T. O’Brien, F Med Sci, DM

Sotoshi Orimo, MD, PhD

Ronald B. Postuma, MD, MSc

Shankar Ramaswamy, MD

Owen A. Ross, PhD

David P. Salmon, PhD

Andrew Singleton, PhD

Angela Taylor, BM

Alan Thomas, PhD

Pietro Tiraboschi, MD

Jon B. Toledo, MD, PhD

John Q. Trojanowski, MD, PhD

Debby Tsuang, MD

Zuzana Walker, MD, FRC Psych

Masahito Yamada, MD, $\mathrm{PhD}$

Kenji Kosaka, MD

Correspondence to

Dr. McKeith:

ian.mckeith@newcastle.ac.uk

Editorial, page 18

Supplemental data at Neurology.org biomarkers, with guidance about optimal methods to establish and interpret these. Clinical signs and symptoms are weighted as core or supportive, and biomarkers as indicative or supportive, based upon their diagnostic specificity and the volume of goodquality evidence available. Although carrying less diagnostic weight, supportive items are often valuable in clinical decision-making, acting as signposts to or adding evidence for a DLB diagnosis. The previous category of suggestive features is no longer used and those items, namely REM sleep behavior disorder (RBD), severe neuroleptic sensitivity, and low dopamine transporter (DAT) imaging, have been reassigned in the new scheme.

The revised criteria (table 1) generate categories of probable and possible DLB, corresponding to terminology previously used, describing the clinical presentations most typical of dementia associated with underlying Lewy-related pathology. Because of considerable pathologic heterogeneity, some dementia presentations associated with Lewy-related pathology are atypical, e.g., if abundant neocortical neuritic plaques and tangles are present in addition to Lewy bodies (LB), the clinical profile may more closely resemble $\mathrm{AD}$ rather than DLB. ${ }^{4,5}$ Such mixed pathology cases are common, explaining why up to half of carefully research-diagnosed patients with AD may have unsuspected Lewy-related pathology at autopsy. ${ }^{6}$ Criteria for the detection of such patients, previously characterized as the LB variant of $\mathrm{AD},{ }^{7}$ remain to be formulated.

Clinical features. Dementia, defined as a progressive cognitive decline of sufficient magnitude to interfere with normal social or occupational functions, or with usual daily activities, is an essential requirement for DLB diagnosis.

Although dementia screens such as the MiniMental State Examination (MMSE) and Montreal Cognitive Assessment are useful to characterize global impairment in DLB, neuropsychological assessment should include tests covering the full range of cognitive domains potentially affected. Disproportionate attentional, executive function, and visual processing deficits relative to memory and naming are typical. ${ }^{8,9}$, e2,e3 Measures of attention/executive function that differentiate DLB from $\mathrm{AD}$ and normal aging and that predict progression from mild cognitive impairment (MCI) to DLB include tests of processing speed and divided/alternating attention, e.g., Stroop tasks, trailmaking tasks, phonemic fluency, and computerized tasks of reaction time. The spatial and perceptual difficulties of DLB often occur early; examples of useful probes include tasks of figure copy, e.g., intersecting pentagons, complex figure copy; visual assembly, e.g., block design, puzzle tasks; spatial matching, e.g., line orientation, size matching tasks; and perceptual discrimination, e.g., incomplete figures, incomplete letters, pareidolia tasks. ${ }^{10, \mathrm{e} 4}$

Memory and object naming tend to be less affected in DLB, and are best evaluated through story recall, verbal list learning, and confrontation naming tasks, although some patients' difficulties may be secondary to speed or retrieval task demands.

No DLB-specific assessment batteries have been developed, although recommendations have been made about suitable existing instruments ${ }^{11}$ and a composite risk score tool has been published. ${ }^{12}$

Core clinical features. Fluctuation. DLB fluctuations have been described in detail previously ${ }^{1,2}$ and are typically delirium-like, ${ }^{\text {es }}$ occurring as spontaneous alterations in cognition, attention, and arousal. They include waxing and waning episodes of behavioral inconsistency, incoherent speech, variable attention, or altered consciousness that involves staring or zoning out. Direct questioning of an informant about fluctuations may not reliably discriminate DLB from $\mathrm{AD}$, but questions about daytime drowsiness, lethargy, staring into space, or episodes of disorganized speech do. These have been incorporated into scales that either score the severity and frequency of fluctuations derived from a clinical interview or use informant reports from semi-structured questionnaires. ${ }^{13-16}$ Recording variations in attentional performance using repeated computer-based tests offers an independent method. ${ }^{\mathrm{e}}{ }^{\text {At }}$ least one measure of fluctuation should be documented when applying DLB diagnostic criteria. Fluctuations may also occur in advanced stages of other dementias, so they best predict DLB when they are present early. ${ }^{\mathrm{e}}$

Visual hallucinations. Recurrent, complex visual hallucinations occur in up to $80 \%$ of patients with DLB and are a frequent clinical signpost to diagnosis. They are typically well-formed, featuring people, children, or animals, sometimes accompanied by related phenomena including passage hallucinations, sense of presence, and visual illusions. ${ }^{\text {e8 }}$ Patients are typically able to report these experiences, as are observant caregivers. Patient responses to their hallucinations vary both in degree of insight and emotional reaction to them. Assessment scales for characterizing and quantifying visual hallucinations are available. ${ }^{17}$

Parkinsonism. Spontaneous parkinsonian features, not due to antidopaminergic medications or stroke, are common in DLB, eventually occurring in over $85 \%$. ${ }^{\text {9 }}$ Parkinsonism in Parkinson disease (PD) is defined as bradykinesia in combination with rest tremor, rigidity, or both. ${ }^{18}$ Many DLB patients' parkinsonism falls short of this, so documentation of only one of these cardinal features is required. Care should be taken particularly in older patients not to misinterpret physical signs due to comorbidity, e.g., 
Table 1 Revised ${ }^{1,2}$ criteria for the clinical diagnosis of probable and possible dementia with Lewy bodies (DLB)

Essential for a diagnosis of DLB is dementia, defined as a progressive cognitive decline of sufficient magnitude to interfere with normal social or occupational functions, or with usual daily activities. Prominent or persistent memory impairment may not necessarily occur in the early stages but is usually evident with progression. Deficits on tests of attention, executive function, and visuoperceptual ability may be especially prominent and occur early.

\section{Core clinical features (The first 3 typically occur early and may persist throughout the course.)}

Fluctuating cognition with pronounced variations in attention and alertness. Recurrent visual hallucinations that are typically well formed and detailed. REM sleep behavior disorder, which may precede cognitive decline.

One or more spontaneous cardinal features of parkinsonism: these are bradykinesia (defined as slowness of movement and decrement in amplitude or speed), rest tremor, or rigidity.

\section{Supportive clinical features}

Severe sensitivity to antipsychotic agents; postural instability; repeated falls; syncope or other transient episodes of unresponsiveness; severe autonomic dysfunction, e.g., constipation, orthostatic hypotension, urinary incontinence; hypersomnia; hyposmia; hallucinations in other modalities; systematized delusions; apathy, anxiety, and depression.

Indicative biomarkers

Reduced dopamine transporter uptake in basal ganglia demonstrated by SPECT or PET. Abnormal (low uptake) ${ }^{123}$ iodine-MIBG myocardial scintigraphy.

Polysomnographic confirmation of REM sleep without atonia.

\section{Supportive biomarkers}

Relative preservation of medial temporal lobe structures on CT/MRI scan Generalized low uptake on SPECT/PET perfusion/metabolism scan with reduced occipital activity \pm the cingulate island sign on FDG-PET imaging

Prominent posterior slow-wave activity on EEG with periodic fluctuations in the pre-alpha/ theta range.

Probable DLB can be diagnosed if:

a. Two or more core clinical features of DLB are present, with or without the presence of indicative biomarkers, or

b. Only one core clinical feature is present, but with one or more indicative biomarkers.

Probable DLB should not be diagnosed on the basis of biomarkers alone.

Possible DLB can be diagnosed if:

a. Only one core clinical feature of DLB is present, with no indicative biomarker evidence, or b. One or more indicative biomarkers is present but there are no core clinical features.

DLB is less likely:

a. In the presence of any other physical illness or brain disorder including cerebrovascular disease, sufficient to account in part or in total for the clinical picture, although these do not exclude a DLB diagnosis and may serve to indicate mixed or multiple pathologies contributing to the clinical presentation, or

b. If parkinsonian features are the only core clinical feature and appear for the first time at a stage of severe dementia.

DLB should be diagnosed when dementia occurs before or concurrently with parkinsonism. The term Parkinson disease dementia (PDD) should be used to describe dementia that occurs in the context of well-established Parkinson disease. In a practice setting the term that is most appropriate to the clinical situation should be used and generic terms such as Lewy body disease are often helpful. In research studies in which distinction needs to be made between DLB and PDD, the existing 1-year rule between the onset of dementia and parkinsonism continues to be recommended. it occurs frequently in autopsy-confirmed cases compared with non-DLB (76\% vs $4 \%) .{ }^{19}$ It often begins many years before other symptoms, may become less vigorous or even quiescent over time, and should be screened for using a scale that allows for patient or bed partner report. ${ }^{23,24}$ Conditions mimicking RBD are common in people with dementia, e. g., confusional awakenings, severe obstructive sleep apnea, and periodic limb movements, all of which must be excluded by careful supplementary questioning to avoid a false-positive diagnosis. If there is any doubt whether a sleep disturbance is due to RBD, referral to a specialist sleep clinic should be made, or polysomnography (PSG) requested.

Supportive clinical features. These are clinical features that are commonly present, sometimes early. Although lacking diagnostic specificity, such symptoms may indicate DLB in a patient with dementia, particularly when they persist over time or if several occur in combination. New to this list is hypersomnia, ${ }^{14}$ usually presenting as excessive daytime sleepiness. Also new is hyposmia, which occurs earlier in DLB than in AD. ${ }^{25}$ Transient episodes of unresponsiveness may represent an extreme form of cognitive fluctuation, difficult to distinguish from true syncope. Severe antipsychotic sensitivity is now listed as supportive, because reduced prescribing of D2 receptor blocking antipsychotics in DLB limits its diagnostic usefulness. ${ }^{\text {ell }}$ Caution about their use remains unchanged.

Biomarkers. Although direct biomarker evidence of LB-related pathology is not yet available for clinical diagnosis, several useful indirect methods are.

Indicative biomarkers. If one or more of these is found, associated with one or more core clinical features, probable DLB should be diagnosed. Dementia without any core clinical features, but with one or more indicative biomarkers, may be classified as possible DLB. Probable DLB should not be diagnosed on the basis of biomarkers alone.

Reduced DAT uptake in basal ganglia demonstrated by SPECT or PET imaging. The utility of DAT imaging in distinguishing DLB from $\mathrm{AD}$ is well-established, with sensitivity (78\%) and specificity $(90 \%) .{ }^{26}$ Figure 1 shows ${ }^{123}$ iodine FP-CIT SPECT images in patients with $\mathrm{AD}$, patients with $\mathrm{DLB}$, and normal controls. When parkinsonism is the only core clinical feature of DLB in a patient with dementia, reduced DAT uptake warrants a probable DLB diagnosis provided that other disorders associated with cognitive impairment and reduced DAT uptake can be excluded, e.g., progressive supranuclear palsy, multisystem atrophy, corticobasal degeneration, and frontotemporal dementia. Normal DAT uptake may be reported in autopsy-confirmed DLB 
either because of minimal brainstem involvement and limited nigral neuron $\operatorname{loss}^{27}$ or a balanced loss of dopamine across the whole striatum, rather than predominantly in the putamen.

Reduced uptake on metaiodobenzylguanidine myocardial scintigraphy. ${ }^{123}$ Iodine-MIBG myocardial scintigraphy quantifies postganglionic sympathetic cardiac innervation, which is reduced in LB disease. ${ }^{e 12, e 13}$ Images from patients with $\mathrm{AD}, \mathrm{DLB}$, and age-matched normal controls are shown in figure 2. Useful sensitivity (69\%) and specificity (87\%) values for discriminating probable DLB from probable AD rise to $77 \%$ and 94\% in milder cases (MMSE $>21$ ). ${ }^{28}$ Studies have generally excluded patients with comorbidities, or taking medicines, which can produce abnormal MIBG images. Clinicians should carefully interpret MIBG results in the light of possible confounding causes, including ischemic heart disease, heart failure, diabetes mellitus, peripheral neuropathies, and medications that may cause reduced uptake including labetalol, reserpine, tricyclic antidepressants, and over-the-counter sympathomimetics. ${ }^{29, \mathrm{e} 14, \mathrm{e} 15}$

PSG confirmation of REM sleep without atonia. PSG demonstration of REM sleep without atonia ${ }^{\text {16,e17 }}$ is desirable whenever feasible, since it is a highly specific predictor of Lewy-related pathology. If the PSG shows REM sleep without atonia in a person with dementia and a history of RBD, there is a $\geq 90 \%$ likelihood of a synucleinopathy, ${ }^{22}$ sufficient to justify a probable DLB diagnosis even in the absence of any other core feature or biomarker (figure 3).

Supportive biomarkers. These are biomarkers consistent with DLB that help the diagnostic evaluation, but without clear diagnostic specificity.

Relative preservation of medial temporal lobe structures on CTI MRI scan. Patients with $\mathrm{AD}$ show greater atrophy of medial temporal lobe (MTL) structures than patients with DLB (figure 1), particularly the hippocampus, which is strongly correlated at autopsy with tangle rather than plaque or LB-related pathology. ${ }^{30}$ Absent or minimal MTL atrophy is therefore consistent with DLB, but unusual in AD. A multisite study with autopsy confirmation found sensitivity (64\%) and specificity (68\%) for separating $\mathrm{AD}$ from DLB. ${ }^{31}$ MTL atrophy in DLB may, however, signal substantial additional $\mathrm{AD}$ neuropathologic change, and predict a more rapid clinical course. ${ }^{32}$

Generalized low uptake on SPECT/PET perfusion/metabolism scan, reduced occipital activity, and the posterior cingulate island sign on FDG-PET imaging. FDG-PET occipital hypometabolism correlates with visual cortex neuropathology in $\mathrm{DLB}^{33}$ and a small, autopsy-confirmed study suggested this could distinguish DLB from AD with

Figure 1 Coronal T1-weighted MRI and ${ }^{123}$ iodine FP-CIT SPECT images in Alzheimer disease (AD), dementia with Lewy bodies (DLB), and normal controls (NC)

A. MRI
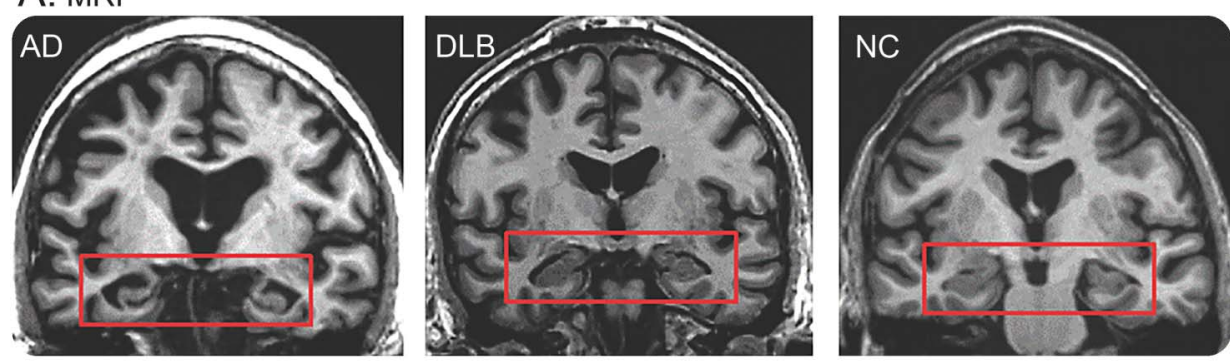

\section{B. FP-CIT SPECT}
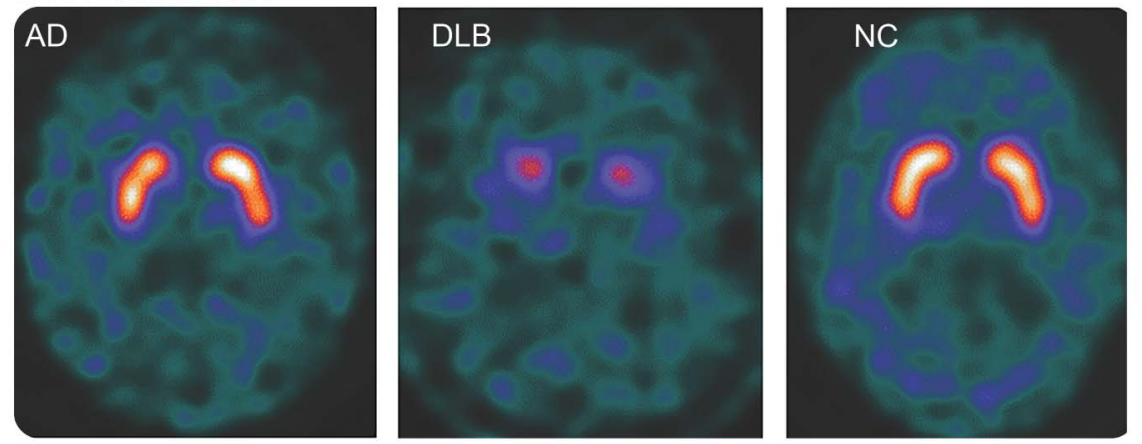

(A) On the MRI, note the relative preservation of medial temporal lobe volume (rectangles) in DLB, which is similar to NC, whereas atrophy is obvious in AD. (B) On the FP-CIT SPECT images, note the minimal uptake in DLB, which is restricted to the caudate (period or full-stop appearance) compared to the robust uptake in the caudate and putamen in AD and NC (comma appearance). Reproduced with permission from Dr. Val Lowe, Mayo Clinic, Rochester, MN. 
Figure 2 123/odine-metaiodobenzylguanidine myocardial imaging in patients with Alzheimer disease (AD), dementia with Lewy bodies (DLB), and age-matched normal controls (NC)

$A D$

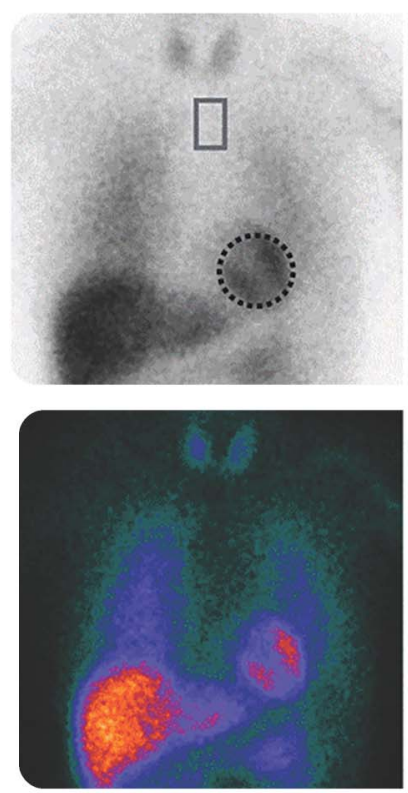

3.94
DLB
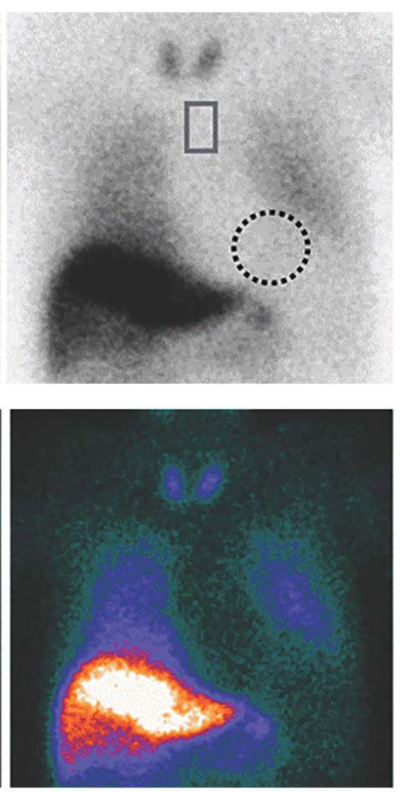

1.34
NC
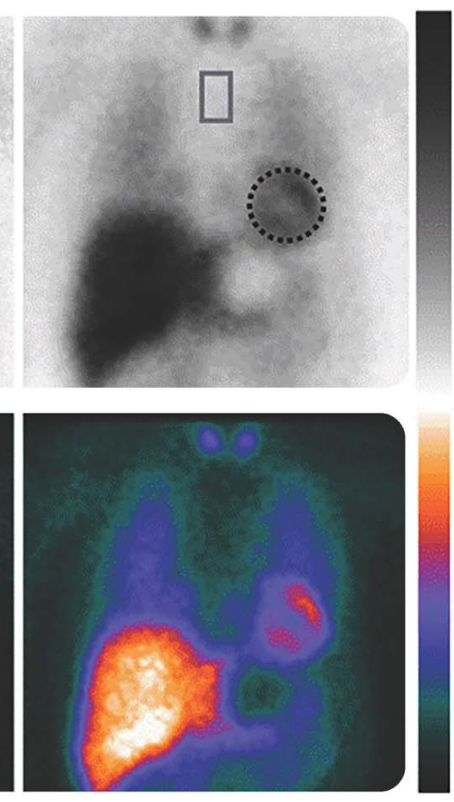

3.44

$\mathrm{H} / \mathrm{M}$ ratio

Images taken 3 hours after injection are shown in 2 color scales, and typical regions of interest are shown on the heart (dotted circle) and upper mediastinum (rectangle). Heart-to-mediastinum (H/M) ratios are standardized to the values comparable to a medium-energy general-purpose collimator condition. ${ }^{\mathrm{e} 12}$ Reproduced with permission from Dr. Kenichi Nakajima, Department of Nuclear Medicine, Kanazawa University.

high accuracy. ${ }^{34}$ Larger studies, earlier in disease, suggest sensitivity $(70 \%)$ and specificity (74\%) slightly lower than needed for an indicative biomarker, although better than that reported for HMPAO-SPECT (65\% and 64\%). ${ }^{35,36}$ Relative preservation of posterior or midcingulate metabolism on FDG-PET (the cingulate island sign) has been described in DLB, ${ }^{37}$ associated with less concurrent neurofibrillary pathology, but with no difference in $\mathrm{A} \beta$ load relative to $\mathrm{AD}$ (figure 4). ${ }^{38}$

Prominent posterior slow-wave EEG activity with periodic fluctuations in the pre-alpha/theta range. Evidence is building to support quantitative EEG as a DLB biomarker, characterized by specific abnormalities in posterior derivations. These include a pre-alpha-dominant frequency, either stable or intermixed with alpha/theta/ delta activities in pseudoperiodic patterns, ${ }^{39}$ which together have a predictive value $>90 \%$ for the diagnosis of DLB compared with AD. ${ }^{\mathrm{e} 18}$ These specific EEG patterns also correlate positively with the severity of clinically observed cognitive fluctuation ${ }^{\mathrm{e} 6}$ and may be seen at the MCI stage. ${ }^{\mathrm{e} 19}$

Other imaging biomarkers. PET imaging shows increased $A \beta$ brain deposition in $>50 \%$ of patients with DLB, limiting its value to distinguish between $\mathrm{AD}$ and $\mathrm{DLB}^{40}$ Combining biomarkers in a multimodal approach can improve diagnostic accuracy in distinguishing $\mathrm{DLB}$ and $\mathrm{AD}^{41}$ and provides information about mixed pathology and multisystem involvement. Tau PET imaging may have an important role, along with MTL atrophy, as a key indicator of coexisting $\mathrm{AD}$ pathology in DLB, predictive of clinical phenotype and progression.

Genetic and fluid biomarkers. The development of broadly applicable CSF, blood, peripheral tissue, or genotypic biomarkers for DLB remains elusive. Although it is clear that there is a substantial genetic contribution to $\mathrm{DLB}^{42,43}$ and that different genetic markers even within the $\alpha$-synuclein gene (SNCA) may be associated with different LB syndromes, ${ }^{44}$ our understanding of the core genes involved remains limited. CSF $\alpha$-synuclein is not yet proven as a biomarker, while $A \beta$, tau, and phospho-tau measurements may be more useful in determining concomitant $\mathrm{AD}$ pathology or predicting cognitive decline. ${ }^{\text {e20 }}$ Glucocerebrosidase $(G B A)$ mutations are overrepresented in $\mathrm{DLB}^{\mathrm{e} 21}$ but most individuals with DLB do not have them. It is premature to recommend genetic testing in a clinical setting, either for confirmation of diagnosis or for prediction of disease, and genetic studies should currently be limited to research settings. 

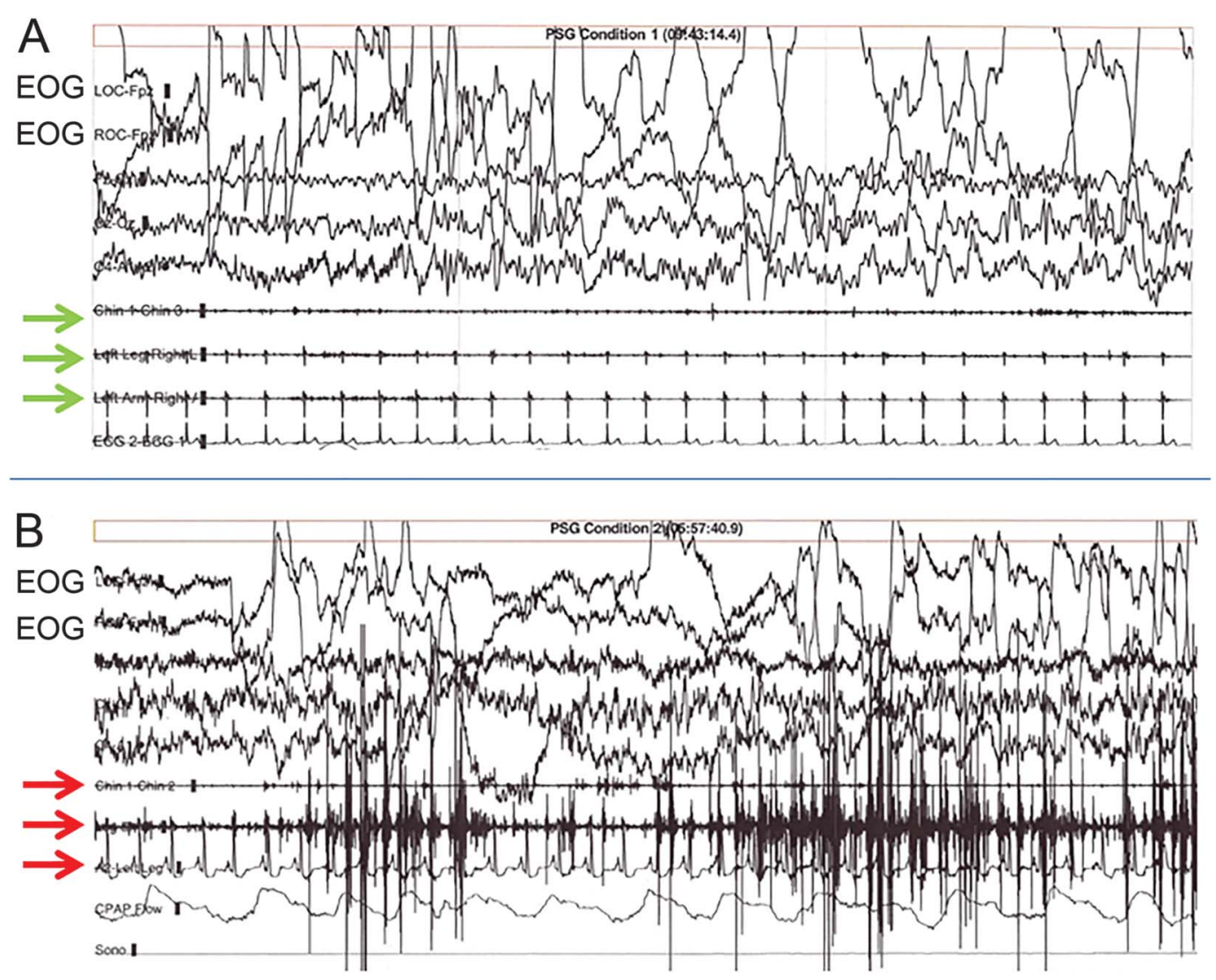

PSG recordings of normal REM sleep (A) and REM sleep without atonia, typical of REM sleep behavior disorder (B).REM are reflected by the high-amplitude, abrupt deviations from baseline in the electro-oculogram (EOG) leads during a 30-second epoch. In (A), note the absence of EMG activity in the submental, leg, and arm leads (green arrows), whereas increased EMG tone is present in the same leads (red arrows) in B, particularly in the middle (arm lead), in this patient.

Clinical management. The management of patients with DLB is complex, requiring a multifaceted approach. Key elements include a thorough initial evaluation to ensure accurate diagnosis; early identification of signs and symptoms requiring intervention; engagement, education, and support of care providers; and a multidisciplinary team approach. Patients with DLB are prone to mental status worsening, including delirium, in the face of comorbid medical disorders. Dopaminergic therapies and anticholinergic medications can adversely affect cognition and behavior, leading to confusion and psychosis. $^{\text {e22,e23 }}$ Treatment of DLB is focused on the cognitive, psychiatric, motor, and other nonmotor symptoms that represent the core or most common features of the disorder. ${ }^{45}$ A combination of pharmacologic and nonpharmacologic approaches is optimal. As the evidence base to support particular treatments remains limited, the recommendations outlined below remain based, in part, upon consensus expert opinion.

Nonpharmacologic interventions. Given both the limited evidence for efficacy and the potential increased morbidity and mortality risks associated with pharmacologic treatments in DLB, there is a need to develop and test nonpharmacologic management strategies. Interventions can be patient- or caregiver-focused, or both. More research in this area has been conducted in $\mathrm{AD}$ and $\mathrm{PD}$ than in DLB, with promising preliminary evidence for exercise (both motor and cognitive benefits), ${ }^{46}$ cognitive training, ${ }^{\text {e24 }}$ and caregiver-oriented education and training to manage psychiatric symptoms including agitation and psychosis. ${ }^{\text {e25,e26 }}$

Pharmacologic management. Cognitive symptoms. Metaanalyses of Class I clinical trials of rivastigmine and donepezil support the use of cholinesterase inhibitors (CHEIs) in DLB for improving cognition, global function, and activities of living, with evidence that even if patients do not improve with CHEIs they are less likely to deteriorate while taking them. ${ }^{47,48}$ The efficacy of memantine in DLB is less clear, but it is well-tolerated and may have benefits, either as monotherapy or adjunctive to a CHEI. ${ }^{47,48}$

Neuropsychiatric symptoms. CHEIs may produce substantial reduction in apathy and improve visual 

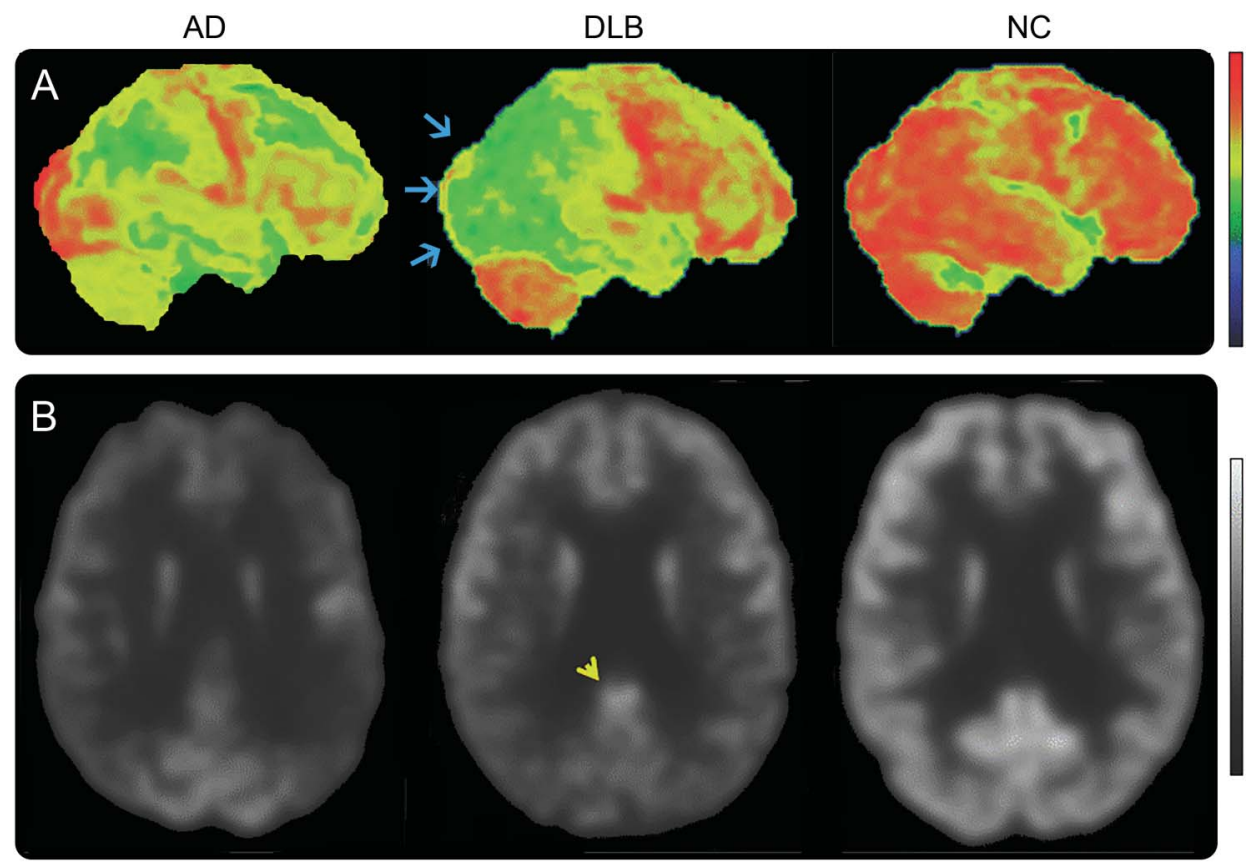

(A) Right lateral metabolic surface map projection. (B) Standard axial view transecting the posterior cingulate region. Occipital lobe metabolism is preserved in $A D$ and NC but reduced (blue arrows) in DLB. Hypometabolism in AD is predominantly in the temporal, parietal, and frontal regions. There is normal metabolism as reflected by the normal ${ }^{18} \mathrm{~F}$-FDG uptake (lighter shade of gray) in the posterior cingulate region (yellow arrowhead) surrounded by reduced ${ }^{18} \mathrm{~F}$-FDG uptake (darker gray) in the adjacent occipital cortex in DLB, representing the cingulate island sign. This contrasts with the relatively reduced ${ }^{18} \mathrm{~F}-\mathrm{FDG}$ uptake in the posterior cingulate and relatively preserved ${ }^{18} \mathrm{~F}$-FDG uptake in the occipital cortex regions in $\mathrm{AD}$. In the control, there is normal ${ }^{18} \mathrm{~F}-\mathrm{FDG}$ uptake in the posterior cingulate, occipital, and other neocortical regions. Color and grayscale sidebars show increasing degrees of deviation from normal as the signal trends lower in the sidebars (red is normal while black is maximally abnormal in color images; white is normal while black is maximally abnormal in grayscale images). Reproduced with permission from Dr. Val Lowe, Mayo Clinic, Rochester, MN.

hallucinations and delusions in DLB. ${ }^{49}$ Since anxiety and agitation are sometimes driven by psychosis, there may be secondary benefits in these. The use of antipsychotics for the acute management of substantial behavioral disturbance, delusions, or visual hallucinations comes with attendant mortality risks in patients with dementia, and particularly in the case of DLB they should be avoided whenever possible, given the increased risk of a serious sensitivity reaction. ${ }^{50}$ Low-dose quetiapine may be relatively safer $^{\text {e27 }}$ than other antipsychotics and is widely used, but a small placebo-controlled clinical trial in DLB was negative. ${ }^{51}$ There is a positive evidence base for clozapine in PD psychosis, but efficacy and tolerability in DLB have not been established. Newer drugs targeting the serotonergic system, such as pimavanserin, ${ }^{52}$ may be alternatives, but controlled clinical trial data in DLB are needed. Although depressive symptoms are common in DLB, trial data are scant. In alignment with general advice on depression in dementia, selective serotonin reuptake inhibitors, serotonin-norepinephrine reuptake inhibitors, and mirtazapine are options in DLB with treatment guided by individual patient tolerability and response.

Motor symptoms. Parkinsonism is often less responsive to dopaminergic treatments in DLB than in PD and their use may be associated with an increased risk of psychosis, although some patients may benefit from levodopa preparations introduced at low doses and increased slowly to the minimum required to minimize motor disability without exacerbating psychiatric symptoms. ${ }^{53,228}$ Patients at risk of falling may benefit from safety assessments, as well as bone mineral density screening, and assessment of vitamin D status, to manage risk of traumatic fractures.

Other symptoms. A wide range of other symptoms can occur in DLB, including autonomic and sleep/wakefulness disturbances, which have profound negative sequelae for quality of life in both patients and their families. In the absence of DLB-specific trial data for these symptoms, clinicians base their treatment decisions on clinical experience, expert opinion, or evidence-based recommendations developed in other diseases, e.g., cautious bedtime use of clonazepam may reduce the risk of sleep-related injuries in 
patients with DLB with RBD but carries a risk of worsening cognition and gait impairment, melatonin being a possibly safer option. ${ }^{54}$

Pathology. Pathologic assessment and diagnostic criteria for $D L B$. The previously published methods for pathologic assessment and diagnosis of DLB should continue to be used with only a few modifications, shown in table 2 , which predicts the likelihood that the pathologic findings will be associated with a typical DLB clinical syndrome, i.e., cases with high likelihood are expected to fulfil clinical criteria for probable DLB, whereas low likelihood cases may have few or no DLB clinical features.

Table 2 assigns categories of AD neuropathologic change according to National Institute on Aging-Alzheimer's Association criteria (no, low, intermediate, and high), ${ }^{55}$ and adds previously omitted categories of Lewy-related pathology including olfactory bulb only ${ }^{56}$ and amygdala predominant. ${ }^{57,58}$ Both of these are considered to be low-likelihood DLB but may in the future be useful in assessing prodromal disease. Further efforts are required to develop better interrater reliability $^{59}$ for Lewy-related disease subtypes (olfactory bulb only, amygdala predominant, brainstem, limbic [transitional], and diffuse neocortical). Table 2 also includes an assessment of substantia nigra neuronal loss (none, mild, moderate, and severe) in order to subclassify cases into those likely or not to have parkinsonism (DLB-P and DLB-no P). ${ }^{60}$

FUTURE DIRECTIONS. Since publication of the 2005 consensus report, DLB has been confirmed as a major dementia subtype, categorized in DSM-5 ${ }^{22}$ as neurocognitive disorder with LB, and distinguished from neurocognitive disorder due to $\mathrm{PD}$. The consensus group remains supportive of the 1-year rule distinguishing DLB from PD dementia, because as originally stated ${ }^{1,2}$ this arbitrary cutoff remains useful, particularly in clinical practice. Based as it is on expert opinion, the time period may need modification when the genetic underpinnings, pathophysiologic mechanisms, and prodromal states of these disorders are sufficiently understood to enable a data-driven solution. e $30, e 31^{-}$

There is an urgent need to develop guidelines and outcome measures for clinical trials in DLB, both symptomatic and disease-modifying, nonpharmacologic and pharmacologic. DLB researchers can build upon experience gained in $\mathrm{AD}$ and $\mathrm{PD}$; additional issues for them to consider include subtyping of patients on the basis of clinical or biomarker criteria and selecting target symptoms and outcome measures appropriate to DLB. It will be necessary to manage potential confounding factors that are common in DLB, e.g., fluctuations in alertness and fatigue, active hallucinations, and concomitant use of cognitive enhancing and psychiatric medications. Such considerations will need to be applied when designing clinical trials across the spectrum of clinical syndrome of DLB from prodromal and presymptomatic stages, still to be identified, to overt dementia.

Suggested strategies to progress critical areas of biological research include collecting samples from large population-based cohorts and developing a publicly available DLB genetic database and a repository for DLB exome data. Family studies are needed to find and confirm genes, requiring clinicians to take detailed family histories seeking evidence not only of DLB, PD, and AD and other dementias, but also of RBD and supportive features.

In order to make progress in deciphering biological mechanisms at play in DLB including $\mathrm{GBA}^{\mathrm{e} 32}$ and inflammatory pathways, ${ }^{\mathrm{e} 33}$ it will be necessary to develop robust animal models that capture the true neuropathologic and behavioral abnormalities of DLB, and to identify possible disease-specific

Table 2 Assessment of the likelihood that the pathologic findings are associated with a typical, dementia with Lewy bodies, clinical syndrome

\begin{tabular}{|c|c|c|c|}
\hline Alzheimer disease neuropathologic change & $\begin{array}{l}\text { NIA-AA } \\
\text { none/low } \\
\text { (Braak } \\
\text { stage 0-II) }\end{array}$ & $\begin{array}{l}\text { NIA-AA } \\
\text { intermediate } \\
\text { (Braak stage } \\
\text { III-IV) }\end{array}$ & $\begin{array}{l}\text { NIA-AA high } \\
\text { (Braak } \\
\text { stage V-VI) }\end{array}$ \\
\hline \multicolumn{4}{|l|}{ Lewy-related pathology } \\
\hline Diffuse neocortical & High & High & Intermediate \\
\hline Brainstem-predominant & Low & Low & Low \\
\hline Amygdala-predominant & Low & Low & Low \\
\hline Olfactory bulb only & Low & Low & Low \\
\hline
\end{tabular}

Abbreviation: NIA-AA = National Institute on Aging-Alzheimer's Association guidelines for the neuropathologic assessment of Alzheimer disease. ${ }^{55}$ 
molecular differences in $\alpha$-synuclein, tau, and $A \beta$ among DLB, PD, PD dementia, and $\mathrm{AD}$. The latter includes characterization of possible molecular strains of misfolded or pathologic $\alpha$-synuclein, posttranslational modifications in degradation and clearance processes, and transmission and propagation. It will be increasingly important to study protein interactions among $\alpha$-synuclein, $A \beta$, and tau. ${ }^{e 34}$ Finally, there is an unmet need to characterize biological effects of identified genetic risk factors, including $A P O E, G B A$, and $S N C A$, as well as to model and analyze gene-environmental interactions.

In order to best advance DLB research, global harmonization efforts are required to create networks of researchers and research participants who share common platforms for data and biomarker collection, outcome measures for clinical-translational research, and shared terminology across language, cultures, and traditions. Consideration might be given to creating an international patient and caregiver association to serve as advocates for private and public funding; identifying obstacles to the pharmaceutical industry sponsoring DLB research; bridging relationships with the $\mathrm{PD}$ and $\mathrm{AD}$ world research communities; creating a plan for reimbursement for DLB clinical care, drugs/devices, and biomarkers; and increasing interdisciplinary and interprofessional communication regarding the challenges facing clinicians, patients, and caregivers. Finally, priority needs to be given to helping patients and carers to inform themselves about the disease, its prognosis, best available treatments, ongoing research, and how to get adequate support.

\section{AUTHOR AFFILIATIONS}

From the Institute of Neuroscience (I.G.M., J.-P.T., J.A., D.B. A. Thomas), Newcastle University, UK; Departments of Neurology (B.F. B.) and Radiology (K. Kantarci), Mayo Clinic (A.L.), Rochester, MN; Neuropathology Laboratory (D.W.D., M. Murray) and Departments of Psychiatry and Psychology (T.J.F.), Neurology (N.R.G.-R.), and Neuroscience (P.M., O.A.R.), Mayo Clinic, Jacksonville, FL; Brain and Mind Centre (G.H.), University of Sydney (S.L.), Australia; Department of Neurology (J.E.D.) and Center for Neurodegenerative Disease Research (V.M.Y.L., J.Q.T.), Perelman School of Medicine at the University of Pennsylvania (D.W., A.C.-P., J.B.T.), Philadelphia; Parkinson's Disease and Mental Illness Research, Education and Clinical Centers (PADRECC and MIRECC) (D.W.), Philadelphia Veterans Affairs Medical Center, PA; Institute of Psychiatry, Psychology, and Neuroscience (D.A., D.f.), King's College London, UK; Centre for Age-Related Diseases (D.A.), Stavanger University Hospital, Norway; Institute for Healthy Aging and Lifespan Studies (I-HeAL) (J.G.), Florida Atlantic University, Boca Raton; Medical School (C.G.B.), University of Exeter; Lewy Body Society (A.B.), Edinburgh, UK; Banner Sun Health Research Institute (T.G.B.), Sun City, AZ; University Hospital of Strasbourg (F. B.); ICube Laboratory (F.B.), CM2R Geriatrics Department and University of Strasbourg-CNRS, France; Departments of Radiology \& Neurology (N.B.), University of Michigan; Department of Veterans Affairs (N.B.), Ann Arbor, MI; Department of Neuroscience, Imaging and Clinical Sciences (L.B.), University G. d'Annunzio of Chieti-Pescara, Chieti, Italy; Department of Molecular Neuroscience (J.B.), Institute of Neurology, UCL, London, UK; Center for Neurodegenerative Science (P.B.), Van Andel Research Institute, Grand Rapids, MI; Neurological
Disorders Research Center (O.E.-A.), Qatar Biomedical Research Institute (QBRI), Ar-Rayyan; Department of Neurosciences (H. Feldman, D. G., D.P.S.), University of California, San Diego; Department of Psychiatry (H. Fujishiro), Nagoya University Graduate School of Medicine, Japan; Department of Neurological Sciences (J.G.G.), Rush University Medical Center, Chicago, IL; Department of Neurology (S.N.G.), MassGeneral Institute for Neurodegenerative Disease, Massachusetts General Hospital, Boston; Department of Neurology and Taub Institute (L.S.H.), Columbia University, New York, NY; Neurology Service (A.I.), Hospital Clinic de Barcelona, Spain; Departments of Neurology and Psychiatry (D.K.), University of North Carolina at Chapel Hill; Department of Epidemiology (W.K.), University of Washington, Seattle; Lou Ruvo Center for Brain Health (J.B.L.), Neurologic Institute, Cleveland Clinic, $\mathrm{OH}$; Thomas Jefferson University (C.L.), Philadelphia, PA; Department of Medicine (M. Masellis), Sunnybrook Health Sciences Centre, University of Toronto, Canada; Division of Neuroscience (E.M.), National Institute on Aging, Baltimore, MD; Paracelsus-Elena-Klinik (B.M.), Kassel, Germany; Department of Pathology (T.J.M.), Stanford University, CA; GE Healthcare (E. Moreno), Medical Affairs, London, UK; Department of Behavioral Neurology and Cognitive Neuroscience (E. Mori), Tohoku University Graduate School of Medicine, Sendai, Japan; Department of Psychiatry (J.T.O.), University of Cambridge, UK; Department of Neurology (S.O.), Kanto Central Hospital, Tokyo, Japan; Department of Neurology (R.B.P.), Montreal General Hospital, Canada; Axovant Sciences, Inc. (S.R.), New York, NY; Laboratory of Neurogenetics (A.S.), NIH, Bethesda, MD; Lewy Body Dementia Association (A. Taylor), Lilburn, GA; Neurology Department (J.B.T.), Houston Methodist Hospital, TX; Division of Neurology/Neuropathology (P.T.), Fondazione I.R.C.C.S., Istituto Neurologico Carlo Besta, Milan, Italy; VA Puget Sound Health Care System (D.T.), Seattle, WA; University College London \& North Essex Partnership University NHS Foundation Trust (Z.W.), UK; Department of Neurology and Neurobiology of Aging (M.Y.), Kanazawa University Graduate School of Medical Sciences; and Yokohama City University Medical Center (K. Kosaka), Japan.

\section{AUTHOR CONTRIBUTIONS}

Ian McKeith: design or conceptualization of the study, analysis or interpretation of the data, drafting or revising the manuscript. Bradley Boeve: design or conceptualization of the study, analysis or interpretation of the data, drafting or revising the manuscript. Dennis Dickson: design or conceptualization of the study, analysis or interpretation of the data, drafting or revising the manuscript. Glenda Halliday: design or conceptualization of the study, analysis or interpretation of the data, drafting or revising the manuscript. John-Paul Taylor: design or conceptualization of the study, analysis or interpretation of the data, drafting or revising the manuscript. Daniel Weintraub: design or conceptualization of the study, analysis or interpretation of the data, drafting or revising the manuscript. Dag Aarsland: design or conceptualization of the study, analysis or interpretation of the data, drafting or revising the manuscript. James Galvin: design or conceptualization of the study, analysis or interpretation of the data, drafting or revising the manuscript. Johannes Attems: design or conceptualization of the study, analysis or interpretation of the data, drafting or revising the manuscript. Clive Ballard: analysis or interpretation of the data, drafting or revising the manuscript. Ashley Bayston: design or conceptualization of the study, analysis or interpretation of the data, drafting or revising the manuscript. Thomas Beach: design or conceptualization of the study, analysis or interpretation of the data, drafting or revising the manuscript. Frédéric Blanc: analysis or interpretation of the data, drafting or revising the manuscript. Nicolaas Bohnen: analysis or interpretation of the data, drafting or revising the manuscript. Laura Bonanni: analysis or interpretation of the data, drafting or revising the manuscript. Jose Bras: analysis or interpretation of the data, drafting or revising the manuscript. Patrik Brundin: analysis or interpretation of the data, drafting or revising the manuscript. David Burn: analysis or interpretation of the data, drafting or revising the manuscript. Alice Chen-Plotkin: analysis or interpretation of the data, drafting or revising the manuscript. John E. Duda: design or conceptualization of the study, analysis or interpretation of the data, drafting or revising the manuscript. Omar El-Agnaf: analysis or interpretation of the data. Howard Feldman: design or conceptualization of the study, analysis or interpretation of the data, drafting or revising the manuscript. Tanis Ferman: design or conceptualization of the study, 
analysis or interpretation of the data, drafting or revising the manuscript. Dominic ffytche: analysis or interpretation of the data. Hiroshige Fujishiro: design or conceptualization of the study, analysis or interpretation of the data. Douglas Galasko: analysis or interpretation of the data, drafting or revising the manuscript. Jennifer Goldman: design or conceptualization of the study, analysis or interpretation of the data, drafting or revising the manuscript. Stephen N. Gomperts: analysis or interpretation of the data, drafting or revising the manuscript. Neill R. Graff-Radford: design or conceptualization of the study, analysis or interpretation of the data, drafting or revising the manuscript. Lawrence S. Honig: analysis or interpretation of the data, drafting or revising the manuscript. Alex Iranzo: analysis or interpretation of the data, drafting or revising the manuscript. Kejal Kantarci: design or conceptualization of the study, analysis or interpretation of the data, drafting or revising the manuscript. Danie Kaufer: analysis or interpretation of the data, drafting or revising the manuscript. Walter Kukull: design or conceptualization of the study, analysis or interpretation of the data, drafting or revising the manuscript. Virginia Lee: analysis or interpretation of the data. Jim Leverenz: design or conceptualization of the study, analysis or interpretation of the data, drafting or revising the manuscript. Simon Lewis: analysis or interpretation of the data, drafting or revising the manuscript. Carol Lippa: design or conceptualization of the study, analysis or interpretation of the data, drafting or revising the manuscript. Angela Lunde: design or conceptualization of the study, analysis or interpretation of the data, drafting or revising the manuscript. Mario Masellis: analysis or interpretation of the data, drafting or revising the manuscript. Eliezer Masliah: analysis or interpretation of the data. Pamela McLean: analysis or interpretation of the data, drafting or revising the manuscript. Brit Mollenhauer: analysis or interpretation of the data, drafting or revising the manuscript. Thomas Montine: analysis or interpretation of the data. Emilio Moreno: analysis or interpretation of the data, drafting or revising the manuscript. Etsuro Mori: analysis or interpretation of the data. Melissa Murray: analysis or interpretation of the data, drafting or revising the manuscript. John O'Brien: design or conceptualization of the study, analysis or interpretation of the data, drafting or revising the manuscript. Satoshi Orimo: analysis or interpretation of the data. Ron Postuma: design or conceptualization of the study, analysis or interpretation of the data, drafting or revising the manuscript. Shankar Ramaswamy: analysis or interpretation of the data, drafting or revising the manuscript. Owen Ross: design or conceptualization of the study, analysis or interpretation of the data, drafting or revising the manuscript. David Salmon: design or conceptualization of the study, analysis or interpretation of the data, drafting or revising the manuscript. Andrew Singleton: design or conceptualization of the study, analysis or interpretation of the data. Angela Taylor: analysis or interpretation of the data, drafting or revising the manuscript. Alan Thomas: analysis or interpretation of the data, drafting or revising the manuscript. Pietro Tiraboschi: analysis or interpretation of the data, drafting or revising the manuscript. Jon Toledo: analysis or interpretation of the data, drafting or revising the manuscript. John Trojanowski: analysis or interpretation of the data, drafting or revising the manuscript. Debby Tsuang: design or conceptualization of the study, analysis or interpretation of the data. Zuzana Walker: design or conceptualization of the study, analysis or interpretation of the data, drafting or revising the manuscript. Masahito Yamada: analysis or interpretation of the data, drafting or revising the manuscript. Kenji Kosaka: analysis or interpretation of the data.

\section{ACKNOWLEDGMENT}

The authors thank Dr. Val Lowe, Mayo Clinic, Rochester, for FP-CIT SPECT and FDG-PET images (figures 1 and 4); and Dr. Kenichi Nakajima, Department of Nuclear Medicine, Kanazawa University, for MIBG myocardial scintigraphy images (figure 2).

\section{STUDY FUNDING}

The DLB Consortium meeting was organized by the Mayo School of Continuous Professional Development (MSCPD) and supported by Acadia Pharmaceuticals, Alzheimer's Association, Axovant Sciences, Banner Health, GE Healthcare, the Lewy Body Dementia Association, the Lewy Body Society, Lundbeck, the National Institute on Aging, the National Institute on Neurologic Disease and Stroke, and an NIH grant (R13 NS095618). Kathy Fuqua, Julie Reed, and colleagues at the MSCPD provided administrative support to the consortium meeting in Fort Lauderdale. I.G.M., D.B., J.-P.T., J.A., and A.T. receive support from the UK NIHR Biomedical Research Centre awarded to the Newcastle upon Tyne Hospitals NHS Foundation Trust and Newcastle University. Travel grant support was provided by the Alzheimer's Research UK ARUK NE Network Centre. B.F.B., D.W.D., K.K., and T.J.F. are supported by the NIH (P50-AG016574) and the Mangurian Foundation for Lewy Body Research. G.H. is a senior principal research fellowship holder from the National Health and Medical Research Council of Australia (1079679). D.A. is a Royal Society Wolfson Research Merit Award Holder and thanks the Wolfson Foundation and the Royal Society for their support. C.G.B. thanks the Maudsley BRC for Mental Health and BRU dementia for supporting his involvement in the work. A.C.-P. receives research support from the NIH (RO1 NS082265, UO1 NS082134, P50 NS053488), the Burroughs Wellcome Fund, the Alzheimer's Association/Michael J. Fox Foundation/Weston Biomarkers Across Neurodegenerative Disease initiative, and the Pechenik Montague Award Fund. D.f. acknowledges support from NIHR Programme Grants for Applied Research (RP-PG-0610-10100 SHAPED). O.E.-A. acknowledges support for OE laboratory from the Michael J. Fox Foundation for Parkinson's Research (New York). S.N.G. receives support from R21 NS 090243 and the National Parkinson's Foundation. O.A.R. is supported through the Mayo Clinic: A Morris K. Udall Parkinson's Disease Research Center of Excellence (NINDS P50 NS072187), NINDS R01 NS078086, the Michael J. Fox Foundation for Parkinson's Research, the Mayo Clinic AD and Related Dementias Genetics Program, and The Little Family Foundation. A.S.'s work is supported by the Intramural Research Program of the National Institute on Aging, Department of Health and Human Services. D.T. acknowledges the work of Cyrus Zabetian, MD, and Ignacio Mata, PhD, from VA Puget Sound Health Care System. J.Q.T. and V.M.Y.L.'s contributions were supported in part by a P50 NS053488 Morris K. Udall Parkinson's Disease Research Center of Excellence grant from NINDS. P.T. acknowledges support from the Italian Ministry of Health "Ricerca Corrente." M.Y. acknowledges support from the Japan Foundation for Neuroscience and Mental Health.

\section{DISCLOSURE}

I. McKeith receives support from the UK NIHR Biomedical Research Centre awarded to the Newcastle upon Tyne Hospitals NHS Foundation Trust and Newcastle University. He has consulted for Axovant Sciences, Takeda, Eisai, and GE Healthcare. B. Boeve has served as an investigator for clinical trials sponsored by GE Healthcare, FORUM Pharmaceuticals, $\mathrm{C} 2 \mathrm{~N}$ Diagnostics, and Axovant Sciences. He receives royalties from the publication of Behavioral Neurology of Dementia (Cambridge Medicine, 2009). He serves on the Scientific Advisory Board of the Tau Consortium. He receives research support from the NIH and the Mangurian Foundation. D. Dickson receives research support from the NIH (P50AG016574, P50-NS072187, P01-AG003949) and CurePSP: Foundation for PSP/CBD and Related Disorders. Dr. Dickson is an editorial board member of Acta Neuropathologica, Annals of Neurology, Brain, Brain Pathology, and Neuropathology, and he is editor-in-chief of American Journal of Neurodegenerative Disease and International Journal of Clinical and Experimental Pathology. G. Halliday consults for the National Health and Medical Research Council of Australia (NHMRC); received travel funds from AAIC, International Society of Neurochemistry, International DLB Conference, AAN, International MSA Conference, NHMRC National Institute for Dementia Research, 2nd Chinese Brain Banking Meeting, and Japanese Neuroscience Society; is on the editorial boards of Acta Neuropathol, J Neural Transm, J Parkinson Dis, Transl Neurodegen, and Neuropathol Appl Neurobiol; receives royalties from Academic Press, Elsevier, and Oxford University Press; receives research grant funding from NHMRC (1008307, 1037746, and 1079679), the Michael J. Fox Foundation, Shake-it-up Australia, Parkinson's NSW, and University of NSW (infrastructure and equipment); and holds stock in Cochlear (2004 on) and NIB Holdings (2007 on). J. Taylor has been a consultant of Lundbeck and received honoraria for talks from GE Healthcare and Flynn Pharmaceuticals. D. Weintraub has received research funding or support from Michael J. Fox Foundation for Parkinson's Research, NIH (NINDS), Novartis Pharmaceuticals, Department of Veterans Affairs, Avid Radiopharmaceuticals, Alzheimer's Disease Cooperative Study, 
and the International Parkinson and Movement Disorder Society; honoraria from AbbVie, Acadia, Biogen, Biotie, Clintrex LLC, Janssen, Merck, Novartis, Pfizer, Teva Pharmaceuticals, UCB, and the CHDI Foundation; license fee payments from the University of Pennsylvania for the QUIP and QUIP-RS; royalties from Wolters Kluwer; and and fees for legal consultation for a lawsuit related to antipsychotic prescribing in a patient with Parkinson disease. D. Aarsland has received research support and/or honoraria from Astra-Zeneca, H. Lundbeck, Novartis Pharmaceuticals, and GE Health, and serves as a paid consultant for H. Lundbeck and Axovant. J. Galvin receives research support from Biogen, Axovant, NIH, Association for Frontotemporal Degeneration, and Florida Department of Health, and is a consultant for Biogen and Eisai. J. Attems reports no disclosures relevant to the manuscript. C. Ballard has received honoraria and grant funding from Acadia Pharmaceuticals, which manufactures pimavanserin. Other financial disclosures in the last 2 years include the following: contract grant funding from Lundbeck, Takeda, and Axovant pharmaceutical companies and honoraria from Lundbeck, Lilly, Otusaka, and Orion pharmaceutical companies. A. Bayston reports no disclosures relevant to the manuscript. T. Beach is a consultant to GE Healthcare and Avid Radiopharmaceuticals, performs contracted research for Avid Radiopharmaceuticals and Navidea Biopharmaceuticals, and receives research funding from NIH grant (P30AG019610), the Arizona Department of Health and Human Services, and the Michael J. Fox Foundation for Parkinson's Research. F. Blanc has received speaker's honoraria and travel expenses from Roche, Biogen Idec, Novartis, and Merck Serono. N. Bohnen receives research support from the NIH, Department of Veterans Affairs, and the Michael J. Fox Foundation. L. Bonanni reports no disclosures relevant to the manuscript. J. Bras was supported by a fellowship from the Alzheimer's Society and funding from the Lewy Body Society and Parkinson's UK P. Brundin has received commercial support as a consultant from Renovo Neural, Inc., Roche, Teva/Lundbeck, and AbbVie. He has received commercial support for grants/research from Renovo and Teva/Lundbeck. Dr. Brundin has ownership interests in Acousort AB and Parkcell AB. D. Burn and A. Chen-Plotkin report no disclosures relevant to the manuscript. J. Duda serves on the Editorial Board for npj Parkinson's Disease and has received research support from the US Department of Veterans Affairs, NIH, and the Michael J. Fox Foundation for Parkinson's Research. O. El-Agnaf reports no disclosures relevant to the manuscript. $\mathrm{H}$. Feldman receives research funding from the NIH, the Canadian Institutes of Health Research, the Weston Foundation, UC Cures for Alzheimer's Disease, and Heart and Stroke Foundation of Canada. He has served as coinvestigator on clinical trials sponsored by TauRx, Hoffman LaRoche, and Lilly. He currently serves on the scientific advisory boards for the Tau Consortium, Tau Rx, and the Alzheimer Society of Canada Research Policy. He has performed service agreements for UCSD/UBC with Genentech Banner Health, Eisai, Arena, and Merck. He receives royalties for the publication of An Atlas of Alzheimer's Disease (Informa Health, 2007). He has a US patent: PCT/US 2007/07008. T. Ferman, D. ffytche, and H. Fujishiro report no disclosures relevant to the manuscript. D. Galasko is funded by NIH grant AG05131, the Michael J. Fox Foundation, and the California Institute for Regenerative Medicine. He has received funding from vTv Pharmaceuticals and Eli Lilly, Inc., for consultation, from Eli Lilly and Prothena for service on Data Safety Boards, and payment from Biomed Central as Editor for Alzheimer's Research and Therapy. J. Goldman has received grant/research support from the NIH, Michael J. Fox Foundation, Rush University, Parkinson Disease Foundation, Acadia, and Biotie (site PI), consulting fees from Acadia, Biogen, Pfizer, and Teva, and honoraria from the International Parkinson and Movement Disorder Society, American Academy of Neurology, MedEdicus, and Pri-Med. S. Gomperts reports no disclosures relevant to the manuscript. N. Graff-Radford is in a multicenter study on Lewy body disease for Axovant and is taking part in multicenter studies with Eli Lilly, Biogen, and TauRX. He has consulted for Cytox. L. Honig has performed consulting for Bristol-Myers Squibb, Forum, Lilly, and Lundbeck pharmaceutical companies; has performed clinical drug trials research funded by AbbVie, Axovant, Bristol-Myers Squibb, C2N, Forum, Genentech, Lilly, Lundbeck, Merck, Pfizer, Roche, TauRx, and vTv pharmaceutical companies; receives compensation from editorial board activities of JAMA Neurology; and receives research support from NIH. A. Iranzo reports no disclosures relevant to the manuscript. K. Kantarci serves on the Data Safety Monitoring Board for Takeda Pharmaceuticals. She is funded by the NIH. D. Kaufer served as a consultant to Janssen Research and Development and was a member of the Scientific Advisory Board for Takeda/Zinfandel. He serves as a consultant to Axovant Sciences, Inc., is a member of the Scientific Advisory Board of the FTD Disorders Registry, is a member of the Scientific Advisory Council of the Lewy Body Dementia Association, and is a member of the Board of Directors of Alzheimer's North Carolina. He receives research support from NIH, TauRx Therapeutics, Navidea Biopharmaceuticals, Axovant Sciences, Neurim Pharmaceuticals, and AbbVie. W. Kukull is funded primarily by NIH grant U01 AG016976 "National Alzheimer's Coordinating Center" and has no other relevant disclosures. He is a Senior Associate Editor for Alzheimer's and Dementia and is also on the editorial board of Alzheimer's Disease and Associated Disorders (nonrenumerated positions). V. Lee may accrue revenue in the future on patents submitted by the University of Pennsylvania wherein she is coinventor and she received revenue from the sale of Avid to Eli Lily as coinventor on imaging-related patents submitted by the University of Pennsylvania. She receives research support from the NIH, GSK, Janssen, Biogen, and several nonprofits. J. Leverenz has served as a consultant for Axovant, GE Healthcare, Navidea Biopharmaceuticals, and Takeda and is funded by grants from the Alzheimer's Drug Discovery Fund, Genzyme/Sanofi, Jane and Lee Seidman Fund, Lewy Body Dementia Association, Michael J. Fox Foundation, and NIH (RF1AG051495, P50NS062684, U01NS100610). S. Lewis, C. Lippa, and A. Lunde report no disclosures relevant to the manuscript. M. Masellis has no disclosures relating to this work. Outside of this work, Dr. Masellis served as an Associate Editor for Current Pharmacogenomics and Personalized Medicine; served as an advisor to Bioscape Medical Imaging $\mathrm{CRO}$, UCB, and GE Healthcare; received honoraria and travel/accommodations/meeting expenses from Novartis and Teva; received royalties from Henry Stewart Talks Ltd.; received peer-reviewed research grants from Canadian Institutes of Health Research, Early Researcher AwardMinistry of Economic Development and Innovation of Ontario, Ontario Brain Institute, Sunnybrook AFP Innovation Fund, Alzheimer's Drug Discovery Foundation (ADDF), Brain Canada, Heart and Stroke Foundation Centre for Stroke Recovery, Weston Brain Institute, and Washington University; received investigator-initiated research support from Teva; received contract research support from Axovant; and received salary support from the Department of Medicine at Sunnybrook Health Sciences Centre and University of Toronto and from the Sunnybrook Foundation. In addition, Dr. Masellis has a patent US 14/674,606 pending, a patent PCT/US15/023618 pending, a patent AR 20150101010 pending, and a patent TW 104110766 pending. E. Masliah and P. McLean report no disclosures relevant to the manuscript. B. Mollenhauer has received independent research grants from TEVA-Pharma, Desitin, Boehringer Ingelheim, and GE Healthcare, and honoraria for consultancy from Bayer Schering Pharma AG, Roche, AbbVie, TEVA-Pharma, and Biogen, and for presentations from GlaxoSmithKline, Orion Pharma, and TEVA-Pharma, and travel costs from TEVA-Pharma. B.M. is a member of the executive steering committee of the Parkinson Progression Marker Initiative of the Michael J. Fox Foundation for Parkinson's Research and has received grants from the BMBF, EU, Deutsche Parkinson Vereinigung, Michael J. Fox Foundation for Parkinson's Research, and Stifterverband für die deutsche Wissenschaft, and has scientific collaborations with Roche, Bristol-Myers Squibb, Ely Lilly, Covance, and Biogen. T. Montine reports no disclosures relevant to the manuscript. E. Moreno is a full employee of GE Healthcare and has been involved in the clinical development of DaTSCAN for the diagnosis of DLB. E. Mori received honoraria from serving on the scientific advisory board of Eisai, grants and personal fees from Eisai, Daiichi Sankyo, Novartis, and FUJIFILM RI, and personal fees from Johnson \& Johnson, Ono, and Nihon MediPhysics. M. Murray is funded by the Ed and Ethel Moore Alzheimer's Disease Research Program (6AZ01) and Gerstner Family Career Development Award. J. O’Brien has acted as a consultant for GE Healthcare, Cytox, TauRx, Axona, Piramal, and Lilly and has received grants from Avid (Lilly). S. Orimo received honoraria for sponsored lectures from FUJIFILM RI Pharma Co Ltd. R. Postuma received grants from the Fonds de la Recherche en Sante Quebec, the Canadian Institute of Health Research, the Parkinson Society, the Weston-Garfield Foundation, and the Webster Foundation, as well as funding for consultancy 
from Biotie and Roche, and speaker fees from Novartis Canada and Teva Neurosciences. S. Ramaswamy is an employee of Axovant Sciences, Inc. He has been involved in the design and execution of the clinical trials in Lewy body dementia conducted by Axovant. O. Ross reports no disclosures relevant to the manuscript. D. Salmon is a consultant for Takeda Pharmaceuticals and is supported by NIA grant AG05131. A. Singleton is an employee of the Intramural Program of the NIH. A. Taylor is an employee of the Lewy Body Dementia Association. A. Thomas has received support from GE Healthcare, the manufacturer of 123I-FPCIT (DaTSCAN), for investigator-led research. P. Tiraboschi reports no disclosures relevant to the manuscript. J. Toledo has received research support from Eli-Lilly. J. Trojanowski may accrue revenue in the future on patents submitted by the University of Pennsylvania wherein he is coinventor and he received revenue from the sale of Avid to Eli Lilly as coinventor on imaging-related patents submitted by the University of Pennsylvania. He receives research support from the NIH, GSK, Janssen, Biogen, and several nonprofits. D. Tsuang serves on the Editorial Board of the American Journal of Medical Genetics, Neuropsychiatric Section, and receives research funding from the NIH and Veterans Affairs Research and Development. Z. Walker has received funding for travel, consultancy, speaker fees, and research support from GE Healthcare (GEHC). M. Yamada received honoraria for sponsored lectures and research grant from Fujifilm RI Pharma Co. Ltd. K. Kosaka reports no disclosures relevant to the manuscript. Go to Neurology.org for full disclosures.

Received September 30, 2016. Accepted in final form March 30, 2017.

\section{REFERENCES}

1. McKeith IG, Galasko D, Kosaka K, et al. Consensus guidelines for the clinical and pathologic diagnosis of dementia with Lewy bodies (DLB): report of the Consortium on DLB International Workshop. Neurology 1996; 47:1113-1124.

2. McKeith IG, Dickson DW, Lowe J, et al. Dementia with Lewy bodies: diagnosis and management: third report of the DLB Consortium. Neurology 2005;65:1863-1872.

3. Vann Jones SA, O'Brien JT. The prevalence and incidence of dementia with Lewy bodies: a systematic review of population and clinical studies. Psychol Med 2014;44:673-683.

4. Tiraboschi P, Attems J, Thomas A, et al. Clinicians' ability to diagnose dementia with Lewy bodies is not affected by beta-amyloid load. Neurology 2015;84:496-499.

5. Weisman D, Cho M, Taylor C, Adame A, Thal LJ, Hansen LA. In dementia with Lewy bodies, Braak stage determines phenotype, not Lewy body distribution. Neurology 2007;69:356-359.

6. Toledo JB, Cairns NJ, Da X, et al. Clinical and multimodal biomarker correlates of ADNI neuropathological findings. Acta Neuropathol Commun 2013;1:65.

7. Hansen L, Salmon D, Galasko D, et al. The Lewy body variant of Alzheimer's disease: a clinical and pathologic entity. Neurology 1990;40:1-8.

8. Hamilton JM, Landy KM, Salmon DP, Hansen LA, Masliah E, Galasko D. Early visuospatial deficits predict the occurrence of visual hallucinations in autopsy-confirmed dementia with Lewy bodies. Am J Geriatr Psychiatry 2012;20:773-781.

9. Ferman TJ, Smith GE, Boeve BF, et al. Neuropsychological differentiation of dementia with Lewy bodies from normal aging and Alzheimer's disease. Clin Neuropsychol 2006;20:623-636.

10. Yokoi K, Nishio Y, Uchiyama M, Shimomura T, Iizuka O, Mori E. Hallucinators find meaning in noises: pareidolic illusions in dementia with Lewy bodies. Neuropsychologia 2014;56:245-254.
11. Walker Z, Possin KL, Boeve BF, Aarsland D. Lewy body dementias. Lancet 2015;386:1683-1697.

12. Galvin JE. Improving the clinical detection of Lewy body dementia with the Lewy body composite risk score. Alzheimers Dement 2015;1:316-324.

13. Bradshaw JSM, Hopwood M, Anderson V, Brodtmann A. Fluctuating cognition in dementia with Lewy bodies and Alzheimer's disease is qualitatively distinct. J Neurol Neurosurg Psychiatry 2004;75:382-387.

14. Ferman TJ, Smith GE, Boeve BF, et al. DLB fluctuations: specific features that reliably differentiate from $A D$ and normal aging. Neurology 2004;62:181-187.

15. Walker MP, Ayre GA, Cummings JL, et al. The clinician assessment of fluctuation and the one day fluctuation assessment scale: two methods to assess fluctuating confusion in dementia. Br J Psychiatry 2000;177:252256.

16. Lee DR, McKeith I, Mosimann U, et al. The dementia cognitive fluctuation scale, a new psychometric test for clinicians to identify cognitive fluctuations in people with dementia. Am J Geriatr Psychiatry 2014;22:926-935.

17. Mosimann UP, Collerton D, Dudley R, et al. A semistructured interview to assess visual hallucinations in older people. Int J Geriatr Psychiatry 2008;23:712-718.

18. Postuma RB, Berg D, Stern M, et al. MDS clinical diagnostic criteria for Parkinson's disease. Mov Disord 2015; 30:1591-1599.

19. Ferman TJ, Boeve BF, Smith GE, et al. Inclusion of RBD improves the diagnostic classification of dementia with Lewy bodies. Neurology 2011;77:875-882.

20. Postuma RB, Gagnon JF, Vendette M, Fantini ML, Massicotte-Marquez J, Montplaisir J. Quantifying the risk of neurodegenerative disease in idiopathic REM sleep behavior disorder. Neurology 2009;72:1296-1300.

21. Iranzo A, Fernandez-Arcos A, Tolosa E, et al. Neurodegenerative disorder risk in idiopathic REM sleep behavior disorder: study in 174 patients. PLoS One 2014;9:e89741.

22. Boeve BF, Silber MH, Ferman TJ, et al. Clinicopathologic correlations in 172 cases of rapid eye movement sleep behavior disorder with or without a coexisting neurologic disorder. Sleep Med 2013;14:754-762.

23. Boeve BF, Molano JR, Ferman TJ, et al. Validation of the Mayo Sleep Questionnaire to screen for REM sleep behavior disorder in an aging and dementia cohort. Sleep Med 2011;12:445-453.

24. Postuma RB, Arnulf I, Hogl B, et al. A single-question screen for rapid eye movement sleep behavior disorder: a multicenter validation study. Mov Disord 2012;27:913-916.

25. Williams SS, Williams J, Combrinck M, Christie S, Smith $\mathrm{AD}, \mathrm{McShane} \mathrm{R}$. Olfactory impairment is more marked in patients with mild dementia with Lewy bodies than those with mild Alzheimer disease. J Neurol Neurosurg Psychiatry 2009;80:667-670.

26. McKeith I, O'Brien J, Walker Z, et al. Sensitivity and specificity of dopamine transporter imaging with 123IFP-CIT SPECT in dementia with Lewy bodies: a phase III, multicentre study. Lancet Neurol 2007;6:305-313.

27. Colloby SJ, McParland S, O’Brien JT, Attems J. Neuropathological correlates of dopaminergic imaging in $\mathrm{Alz}$ heimer's disease and Lewy body dementias. Brain 2012; 135:2798-2808.

28. Yoshita M, Arai H, Arai H, et al. Diagnostic accuracy of I123-meta-iodobenzylguanidine myocardial scintigraphy in 
dementia with Lewy bodies: a multicenter study. PLoS One 2015;10:e0120540.

29. Tiraboschi P, Corso A, Guerra UP, et al. (123) I-2betacarbomethoxy-3beta-(4-iodophenyl)-N-(3-fluoropropyl) nortropane single photon emission computed tomography and (123) I-metaiodobenzylguanidine myocardial scintigraphy in differentiating dementia with Lewy bodies from other dementias: a comparative study. Ann Neurol 2016;80:368-378.

30. Burton EJ, Barber R, Mukaetova-Ladinska EB, et al. Medial temporal lobe atrophy on MRI differentiates Alzheimers disease from dementia with Lewy bodies and vascular cognitive impairment: a prospective study with pathological verification of diagnosis. Brain 2009;132: 195-203.

31. Harper L, Fumagalli GG, Barkhof F, et al. MRI visual rating scales in the diagnosis of dementia: evaluation in 184 post-mortem confirmed cases. Brain 2016;139:12111225.

32. Nedelska Z, Ferman TJ, Boeve BF, et al. Pattern of brain atrophy rates in autopsy-confirmed dementia with Lewy bodies. Neurobiol Aging 2015;36:452-461.

33. Higuchi $\mathrm{M}$, Tashiro $\mathrm{M}$, Arai $\mathrm{H}$, et al. Glucose hypometabolism and neuropathological correlates in brains of dementia with Lewy bodies. Exp Neurol 2000;162: 247-256.

34. Minoshima S, Foster NL, Sima AAF, Frey KA, Albin RL, Kuhl DE. Alzheimer's disease versus dementia with Lewy bodies: cerebral metabolic distinction with autopsy confirmation. Ann Neurol 2001;50:358-365.

35. Lobotesis K, Fenwick JD, Phipps A, et al. Occipital hypoperfusion on SPECT in dementia with Lewy bodies but not AD. Neurology 2001;56:643-649.

36. O'Brien JT, Firbank MJ, Davison C, et al. F-18-FDG PET and perfusion SPECT in the diagnosis of Alzheimer and Lewy body dementias. J Nucl Med 2014;55:19591965.

37. Lim SM, Katsifis A, Villemagne VL, et al. The F-18-FDG PET cingulate island sign and comparison to I-123-betaCIT SPECT for diagnosis of dementia with Lewy bodies. J Nucl Med 2009;50:1638-1645.

38. Graff-Radford J, Murray ME, Lowe VJ, et al. Dementia with Lewy bodies basis of cingulate island sign. Neurology 2014;83:801-809.

39. Bonanni L, Thomas A, Tiraboschi P, Perfetti B, Varanese $S$, Onofrj M. EEG comparisons in early Alzheimers disease, dementia with Lewy bodies and Parkinson's disease with dementia patients with a 2-year follow-up. Brain 2008;131:690-705.

40. Petrou M, Dwamena BA, Foerster BR, et al. Amyloid deposition in Parkinson's disease and cognitive impairment: a systematic review. Mov Disord 2015;30:928-935.

41. Kantarci K, Lowe VJ, Boeve BF, et al. Multimodality imaging characteristics of dementia with Lewy bodies. Neurobiol Aging 2012;33:2091-2105.

42. Guerreiro R, Escott-Price V, Darwent L, et al. Genomewide analysis of genetic correlation in dementia with Lewy bodies, Parkinson's and Alzheimer's diseases. Neurobiol Aging 2016:38;214.e7-214.e10.

43. Peuralinna T, Myllykangas L, Oinas M, et al. Genomewide association study of neocortical Lewy-related pathology. Ann Clin Transl Neurol 2015;2:920-931.
44. Guella I, Evans DM, Szu-Tu C, et al. Alpha-synuclein genetic variability: a biomarker for dementia in Parkinson disease. Ann Neurol 2016;79:991-999.

45. Boot BP. Comprehensive treatment of dementia with Lewy bodies. Alzheimers Res Ther 2015;7:45.

46. Uc EY, Doerschug KC, Magnotta V, et al. Phase I/II randomized trial of aerobic exercise in Parkinson disease in a community setting. Neurology 2014;83:413-425.

47. Wang HF, Yu JT, Tang SW, et al. Efficacy and safety of cholinesterase inhibitors and memantine in cognitive impairment in Parkinson's disease, Parkinson's disease dementia, and dementia with Lewy bodies: systematic review with meta-analysis and trial sequential analysis. J Neurol Neurosurg Psychiatry 2015;86:135-143.

48. Stinton C, McKeith I, Taylor JP, et al. Pharmacological management of Lewy body dementia: a systematic review and meta-analysis. Am J Psychiatry 2015;172: 731-742.

49. McKeith I, Del Ser T, Spano P, et al. Efficacy of rivastigmine in dementia with Lewy bodies: a randomised, double-blind, placebo-controlled international study. Lancet 2000;356:2031-2036.

50. McKeith I, Fairbairn A, Perry R, Thompson P, Perry E. Neuroleptic sensitivity in patients with senile dementia of Lewy body type. BMJ 1992;305:673-678.

51. Kurlan R, Cummings J, Raman R, Thal L. Quetiapine for agitation or psychosis in patients with dementia and parkinsonism. Neurology 2007;68:1356-1363.

52. Cummings J, Isaacson S, Mills R, et al. Pimavanserin for patients with Parkinson's disease psychosis: a randomised, placebo-controlled phase 3 trial. Lancet 2014;383:533540.

53. Goldman JG, Goetz CG, Brandabur M, Sanfilippo M, Stebbins GT. Effects of dopaminergic medications on psychosis and motor function in dementia with Lewy bodies. Mov Disord 2008;23:2248-2250.

54. Aurora RN, Zak RS, Maganti RK, et al. Best practice guide for the treatment of REM sleep behavior disorder (RBD). J Clin Sleep Med 2010;6:85-95.

55. Montine TJ, Phelps CH, Beach TG, et al. National Institute on Aging-Alzheimer's Association guidelines for the neuropathologic assessment of Alzheimer's disease: a practical approach. Acta Neuropathol 2012;123:1-11.

56. Beach TG, Adler CH, Lue L, et al. Unified staging system for Lewy body disorders: correlation with nigrostriatal degeneration, cognitive impairment and motor dysfunction. Acta Neuropathol 2009;117:613-634.

57. Fujishiro H, Tsuboi Y, Lin W-L, Uchikado H, Dickson DW. Co-localization of tau and alpha-synuclein in the olfactory bulb in Alzheimer's disease with amygdala Lewy bodies. Acta Neuropathol 2008;116:17-24.

58. Uchikado H, Lin W-L, DeLucia MW, Dickson DW. Alzheimer disease with amygdala Lewy bodies: a distinct form of alpha-synucleinopathy. J Neuropathol Exp Neurol 2006;65:685-697.

59. Alafuzoff I, Parkkinen L, Al-Sarraj S, et al. Assessment of alpha-synuclein pathology: a study of the BrainNet Europe consortium. J Neuropathol Exp Neurol 2008; 67:125-143.

60. Dickson DW, Braak H, Duda JE, et al. Neuropathological assessment of Parkinson's disease: refining the diagnostic criteria. Lancet Neurol 2009;8:1150-1157. 


\section{Neurology}

\section{Diagnosis and management of dementia with Lewy bodies: Fourth consensus report of the DLB Consortium}

Ian G. McKeith, Bradley F. Boeve, Dennis W. Dickson, et al.

Neurology 2017;89;88-100 Published Online before print June 7, 2017

DOI 10.1212/WNL.0000000000004058

This information is current as of June 7, 2017

Neurology ${ }^{\circledR}$ is the official journal of the American Academy of Neurology. Published continuously since 1951, it is now a weekly with 48 issues per year. Copyright Copyright $@ 2017$ The Author(s). Published by Wolters Kluwer Health, Inc. on behalf of the American Academy of Neurology.. All rights reserved. Print ISSN: 0028-3878. Online ISSN: 1526-632X.

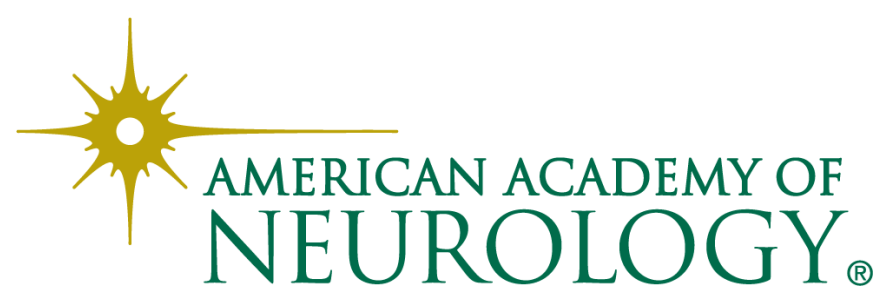




\section{Updated Information \& Services}

\section{Supplementary Material}

\section{References}

Citations

Subspecialty Collections

Permissions \& Licensing

\section{Reprints}

including high resolution figures, can be found at:

http://n.neurology.org/content/89/1/88.full

Supplementary material can be found at: http://n.neurology.org/content/suppl/2017/06/07/WNL.0000000000004 058.DC1

http://n.neurology.org/content/suppl/2017/06/07/WNL.0000000000004 058.DC2

This article cites 60 articles, 19 of which you can access for free at: http://n.neurology.org/content/89/1/88.full\#ref-list-1

This article has been cited by 69 HighWire-hosted articles: http://n.neurology.org/content/89/1/88.full\#\#otherarticles

This article, along with others on similar topics, appears in the following collection(s):

Assessment of cognitive disorders/dementia

http://n.neurology.org/cgi/collection/assessment_of_cognitive_disorder s_dementia

Dementia with Lewy bodies

http://n.neurology.org/cgi/collection/dementia_with_lewy_bodies

\section{Parkinson's disease with dementia}

http://n.neurology.org/cgi/collection/parkinsons_disease_with_dementi a

Information about reproducing this article in parts (figures,tables) or in its entirety can be found online at:

http://www.neurology.org/about/about_the_journal\#permissions

Information about ordering reprints can be found online:

http://n.neurology.org/subscribers/advertise

Neurology ${ }^{\circledR}$ is the official journal of the American Academy of Neurology. Published continuously since 1951, it is now a weekly with 48 issues per year. Copyright Copyright ( 2017 The Author(s). Published by Wolters Kluwer Health, Inc. on behalf of the American Academy of Neurology.. All rights reserved. Print ISSN: 0028-3878. Online ISSN: 1526-632X.

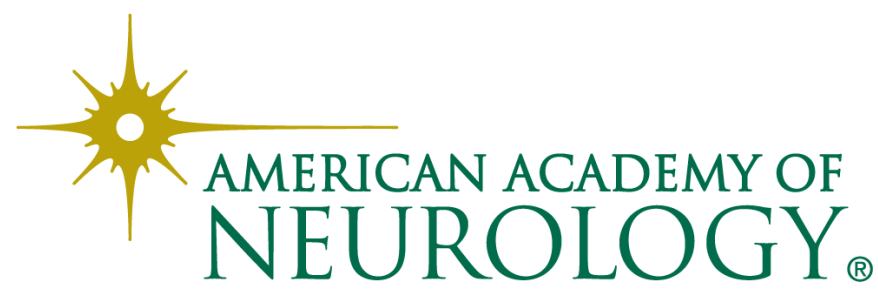

